\title{
Cancer Trends and the Importance of Prevention
}

\author{
Esmat Davoudi Monfared ${ }^{1, *}$ \\ ${ }^{1}$ Health Management Research Center and Department of Community Medicine, Faculty of Medicine, Baqiyatallah University \\ of Medical Sciences, Tehran, Iran
}

Corresponding Author: Esmat Davoudi Monfared, MD, Assistant Professor, Health Management Research Center and Department of Community Medicine, Faculty of Medicine, Baqiyatallah University of Medical Sciences, Tehran, Iran. Tel: +982166602568, E-mail: davoudimonfared@gmail.com

Received October 5, 2017; Accepted November 27, 2017; Online Published December 28, 2017

\begin{abstract}
Cancer is one of the leading causes of death worldwide. The incidence and mortality of cancer is expected to grow rapidly. In Iran cancer morbidity and mortality are gradually changing as a result of economic, demographic and epidemiological transition. Common cancers, such as breast, prostate, colorectal and stomach have different rates of morbidity and mortality in advanced countries and also in Iran. This differentiation has been attributed to prevention measures and activities to control cancer. Cancer prevention and control is one of the most important scientific and public health challenges of this era. A comprehensive cancer control program suggests various ways to control cancer and implements those that are the most cost-effective and beneficial for the largest part of the Iranian population. Thus, it is suggested that a cancer prevention program in three levels of prevention is conducted. The goal of primary prevention is controlling of cancer causes which will be done by preventing human exposure to the risk factors of cancer. Secondary prevention includes early detection of cancer based on the screening program and an effective and timely treatment. Tertiary prevention includes Palliative care to improve the quality of life of patients and their families facing these problems. Considering the existing facilities and the breadth of the primary health care network and human resources and scientific support, a comprehensive cancer control program must be integrated into the primary healthcare network in Iran.

Keywords: Cancer; Prevention; Incidence; Mortality; Iran

Citation: Davoudi Monfared E. Cancer trends and the importance of prevention. Int J Med Rev. 2017;4(4):98-101. doi: 10.29252/ijmr-040403.
\end{abstract}

\section{Introduction}

Cancer is one of the leading causes of death worldwide in developed and developing countries. ${ }^{1}$ The incidence and mortality of cancer is expected to grow rapidly. ${ }^{2}$ This is while the growth of cancer is not the same in different regions of the world regarding the main risk factor of cancer, which includes population grow, age and lifestyle behavior changes that increase the risk of cancer. In developing countries that undergo economic transition, more mechanization of transport and labor, cultural patterns modifying in the role of women and fertility and urbanization, as a result, many lifestyle risk factors, such as smoking, physical inactivity, body weight and changing fertility patterns, are also becoming increasingly prevalent. ${ }^{3}$

In Iran, cancer morbidity and mortality are gradually changing as a result of economic, demographic and epidemiological transition. While cancer was the fifth leading cause of death in the years of 1979 -1981, it was the fourth cause during 1982 to 1986 , and has been the third cause in recent years. ${ }^{4}$
In 2012, the Age- Standardized incidence Rate (ASR) in males and females was 134 and 120 per 100,000, respectively. The estimated mortality for cancer was $90.4 \%$ and $72.2 \%$ at 100,000 in males and females, which represent an increase of $25.4 \%$ and $31.1 \%$, respectively, from the latest report of the National Record of Death (NDR) in 2004..$^{5}$ The incidence of cancer for all types of cancers from 2004 to 2012 has shown an increase i in both genders, which is more prominent in 4 major cancers including stomach, breast, prostate and colorectal cancer. ${ }^{6}$

According to a recent report from GLOBOCAN 2012, breast cancer in women and gastric cancer in men are the most frequently diagnosed cancers and the leading causes of cancer death in Iran. ${ }^{7}$ Breast cancer is the most common cancer of women in the world and in Iran, and is also the leading cause of death in women, accounting for $24.5 \%$ of all cases of cancer and $14.2 \%$ of all deaths in 2012. ${ }^{8}$ The incidence of breast cancer in developed countries, despite the increased prevalence of breast

Copyright (C) 2017 The Author(s). This is an open-access article distributed under the terms of the Creative Commons Attribution License (http://creativecommons.org/licenses/by/4.0), which permits unrestricted use, distribution, and reproduction in any medium, provided the original work is properly cited. 
cancer risk factors and the use of screening for breast cancer, has been rising since 2000. ${ }^{9}$ Compared to the increased and stable incidence patterns, the mortality rate of breast cancer has declined in developed countries since the 1990s. This decline is associated with early detection and appropriate management of treatment. ${ }^{10}$ In contrast, breast cancer morbidity and mortality rates in many other countries, especially developing countries like Iran, continue to increase. ${ }^{6}$ Changes in the lifestyle and reproductive patterns may explain the increased incidence of breast cancer in Iran. ${ }^{11}$ Since the risk factors are also existent in developed countries, it seems that, despite the limitations of mammography, including false negative and non-identifiable cancer, ${ }^{12}$ false positives and excessive diagnosis, ${ }^{13}$ numerous studies have shown that it could improve quality of life and increase treatment options. However, all countries do not have the resources to implement a population-based screening program.

In Iranian men, the most common cancer is stomach which is different from the global pattern of cancer prevalence. This type of cancer has grown over time during the years 2000 to 2012. The incidence rate of stomach cancer has grown in men during 2000 to 2004. This trend has steadily grown till 2012. ${ }^{14}$ In Iran many modifiable factors, including smoking, air pollution, and high salt-preserved foods with low levels of antioxidants along with Helicobacter pylori infection may play an essential role in the pathogenesis of stomach cancer. ${ }^{15}$

In contrast, stomach cancer incidence and mortality rates have been steadily decreased in recent decades in many developed countries. This decreasing pattern would be related to the declining prevalence of Helicobacter pylori infection due to sanitation and antibiotics, in addition to better availability of fresh products. $^{16}$

Prostate cancer is the second most-diagnosed cancer among men in the world. The mortality rate has declined overall in North America, Oceania, Western Europe and northern Europe since the 1990s. ${ }^{17}$ This decrease seems to be due to improved treatment and early detection, although PSA testing partnerships are discussed. ${ }^{18}$

The next major cancer, colon cancer, is the fourth cancer after the stomach cancer, bladder and prostate in men and the second largest in women after breast cancer ${ }^{19}$. Recent studies have shown a rapid increase in colorectal cancer in Iran. However, in 2004, there were no reports of colorectal cancer death. According to the estimations of GLOBOCAN 2012, its mortality is generally upwards. ${ }^{20,21}$

Despite the increasing prevalence in several countries, colorectal cancer deaths in many countries have reduced, possibly due to comprehensive screening and improvements in treatments. ${ }^{22}$

\section{Cancer Prevention}

Cancer prevention and control is one of the most important scientific and public health challenges of this era. Despite the available knowledge, at least one third of the 10 million cancers that occur annually around the world can be prevented. ${ }^{23}$

Controlling different types of cancer has very wide dimensions of scientific knowledge and experiences that addresses complexities of intracellular molecular regulations, individual lifestyles and the social and economic status of a person. It also requires the proper management and best use of available resources for the planning, implementation and evaluation of cancer preventive activities. ${ }^{24}$

A comprehensive cancer control program suggests the various ways to control cancer and implements those that are the most cost-effective and beneficial for the largest part of the Iranian population. The aim of cancer control is a reduction in the incidence and mortality of cancer as well as an improvement in the quality of life of cancer in patients and their families. Thus, conducting a cancer prevention program in three levels of prevention, within the context of an integrated program, is an effective strategy.

\section{Primary Prevention}

The goal of primary prevention is the prevention of cancer causes that will be done by preventing the exposure to the risk factors of cancer. Among the primary prevention activities, tobacco control, healthy diet, physical activities and avoidance of obesity, reducing alcohol use, reducing carcinogenic occupational and environmental exposures, immunization against hepatitis B virus, and avoidance of prolonged exposure to the sun, health education, relating to sexual and reproductive factors associated with cancer should be focused on. ${ }^{25}$

Due to the existence of a comprehensive primary health care network in Iran and also the public referral to the system, it is possible to integrate cancer primary prevention programs in this network.

A large part of cancer primary prevention is in the form of training and education. On the other hand, health education is an important part of primary health care services. It seems that this part of cancer control can be done by specializing in healthy lifestyle education on tobacco and alcohol quitting, healthy diet, physical activities and reduction of obesity.

\section{Secondary Prevention}

Early detection of cancer based on the screening program causes more effective treatment. When the disease is detected earlier in its natural course, prior to the development of symptoms, the final response to treatment is better than in an advanced stage. ${ }^{26}$

It is therefore critical that people are trained to recognize early warning signs of common cancers, such as the lump, debilitating ulcers, abnormal bleeding, chronic dyspepsia, and chronic urticaria, and call for quick 
attention to medical care. This can be promoted by a primary health care system throughout the country with the training of primary health care workers.

In addition, there is currently an effective screening for three common cancers of breast, prostate, and colorectal, with a successful experience of controlling in advanced countries by public screening. ${ }^{27}$ while in Iran it is still not being done publicly.

Public screening for cervical cancer is currently taking place in Iranian women, which, given the prevalence and incidence of the mentioned cancers, it seems that population based screening for them may be essential. Screening for breast cancer: If facilities are available, screening by mammography alone, with or without physical examination of the breasts, plus follow-up of individuals with positive or suspicious findings, will reduce mortality from breast cancer by up to one-third among women aged $40-69$ years. $^{28}$

Screening for colorectal cancer: Evidence to suggest that sigmoidoscopy may be effective for colorectal cancer screening, with benefits lasting for up to ten years. Several trials have evaluated the effect of the Fecal Occult Blood Test (FOBT). ${ }^{29}$

Screening for prostate cancer: Screening for prostate cancer using the Digital Rectal Examination (DRE) is often recommended. Other screening tests include the Prostate Specific Antigen (PSA) and trans-rectal ultrasound. ${ }^{30}$

It is important to highlight the close relationship between cancer early diagnosis and treatment. A great screening program will be inappropriate without an effective treatment. Similarly, the development of treatment capacity without encouraging early detection is not helpful. Developing an effective and timely treatment policy as part of a cancer control program is necessary for a program to succeed.

\section{Tertiary Prevention}

Palliative care is an approach that improves the quality of life of patients and their families facing the problems associated with life-threatening illness like advanced cancer. ${ }^{31}$ Pain relief and palliative care must therefore be regarded as integral and essential elements of a comprehensive cancer control program.

Considering the existing facilities and the breadth of the primary health care network and human resources and scientific support, a comprehensive cancer control program with the ultimate goal of reducing the incidence and mortality of cancer, raising public awareness for the prevention and early diagnosis of cancer, implementing public screening programs and, developing and implementing strict medical guidelines, designing and providing supportive services and palliative care would be integrated into the primary healthcare network. It seems that enabling the capabilities of the country's health network to control cancer is the most effective way to achieve the goals of cancer control.

\section{Conclusions}

Considering the increasing prevalence of common cancers and the increased mortality of these cancers, and given the successful and valuable experiences of some countries in controlling the prevalence and mortality of common cancers by prevention, the integration of a community-based cancer control program into the primary health care system seems critical in this era.

A comprehensive cancer prevention program provides an opportunity for cancer control and also implements programs in the reduction of cancer risk factors, early diagnosis, early detection, and palliative care which are the essential components of the cancer control program. It seems that enabling the capabilities of primary health care network in Iran to control cancer is the most effective way to achieve the goals of cancer prevention programs.

\section{Conflict of Interest Disclosures}

The author declare that they have no conflicts of interest.

\section{Funding}

None.

\section{References}

1. Siegel RL, Miller KD, Jemal A. Cancer statistics, 2018. CA Cancer J Clin. 2018;68(1):7-30. doi: 10.3322/caac.21442. pmid: 29313949.

2. Stewart BWKP, Wild CP. World cancer report 2014. World Health Organization, 2017.

3. Anand P, Kunnumakkara AB, Sundaram $C$, Harikumar KB, Tharakan ST, Lai OS, et al. Cancer is a preventable disease that requires major lifestyle changes. Pharm Res. 2008;25(9):2097-116. doi: 10.1007/s11095-008-9661-9. pmid: 18626751.

4. Ferlay J, Soerjomataram I, Dikshit R, Eser S, Mathers C, Rebelo $\mathrm{M}$, et al. Cancer incidence and mortality worldwide: sources, methods and major patterns in GLOBOCAN 2012. Int J Cancer. 2015;136(5):E359-86. doi: 10.1002/ijc.29210. pmid: 25220842.

5. Mousavi SM, Gouya MM, Ramazani R, Davanlou M, Hajsadeghi N, Seddighi Z. Cancer incidence and mortality in Iran. Ann Oncol. 2009;20(3):556-63. doi: 10.1093/annonc/mdn642. pmid: 19073863.

6. Kolahdoozan S, Sadjadi A, Radmard AR, Khademi H. Five common cancers in Iran. Arch Iran Med. 2010;13(2):143-6. pmid: 20187669.

7. Daroudi R, Akbari Sari A, Nahvijou A, Kalaghchi B, Najafi $\mathrm{M}$, Zendehdel K. The Economic Burden of Breast Cancer in Iran. Iran J Public Health. 2015;44(9):1225-33. pmid: 26587497.

8. Mousavi SM, Montazeri A, Mohagheghi MA, Jarrahi AM, Harirchi I, Najafi $M$, et al. Breast cancer in Iran: an epidemiological review. Breast J. 2007;13(4):383-91. doi: 10.1111/j.1524-4741.2007.00446.x. pmid: 17593043.

9. Jemal A, Center MM, DeSantis C, Ward EM. Global patterns of cancer incidence and mortality rates and trends. Cancer Epidemiol Biomarkers Prev. 2010;19(8):1893-907. doi: 10.1158/1055-9965.EPI-10-0437. pmid: 20647400.

10. Jemal A, Siegel R, Xu J, Ward E. Cancer statistics, 2010. CA Cancer J Clin. 2010;60(5):277-300. doi 10.3322/caac.20073. pmid: 20610543.

11. Heitz AE, Baumgartner RN, Baumgartner KB, Boone SD Healthy lifestyle impact on breast cancer-specific and allcause mortality. Breast Cancer Res Treat. 2018;167(1):171- 
81. doi: 10.1007/s10549-017-4467-2. pmid: 28861753.

12. Moy L, Slanetz PJ, Moore R, Satija S, Yeh ED, McCarthy KA, et al. Specificity of mammography and US in the evaluation of a palpable abnormality: retrospective review. Radiology. 2002;225(1):176-81. doi: 10.1148/radiol.2251010999. pmid: 12355002.

13. Welch HG, Prorok PC, O'Malley AJ, Kramer BS. BreastCancer Tumor Size, Overdiagnosis, and Mammography Screening Effectiveness. N Engl J Med. 2016;375(15):143847. doi: 10.1056/NEJMoa1600249. pmid: 27732805.

14. Yazdizadeh B, Jarrahi AM, Mortazavi H, Mohagheghi MA, Tahmasebi S, Nahvijo A. Time trends in the occurrence of major Gl cancers in Iran. Asian Pac J Cancer Prev. 2005;6(2):130-4. pmid: 16101320.

15. Malekzadeh R, Derakhshan MH, Malekzadeh Z. Gastric cancer in Iran: epidemiology and risk factors. Arch Iran Med. 2009;12(6):576-83. pmid: 19877751.

16. Riboli E, Norat T. Epidemiologic evidence of the protective effect of fruit and vegetables on cancer risk. Am J Clin Nutr. 2003;78(3 Suppl):559S-69S. doi: 10.1093/ajcn/78.3.559S. pmid: 12936950

17. Jemal A, Siegel R, Ward E, Murray T, Xu J, Smigal C, et al. Cancer statistics, 2006. CA Cancer J Clin. 2006;56(2):10630. pmid: 16514137.

18. Catalona WJ, Southwick PC, Slawin KM, Partin AW, Brawer MK, Flanigan RC, et al. Comparison of percent free PSA, PSA density, and age-specific PSA cutoffs for prostate cancer detection and staging. Urology. 2000;56(2):255-60. pmid: 10925089.

19. Jemal A, Siegel R, Ward E, Hao Y, Xu J, Murray T, et al. Cancer statistics, 2008. CA Cancer J Clin. 2008;58(2):71-96. doi: 10.3322/CA.2007.0010. pmid: 18287387.

20. Dolatkhah R, Somi MH, Bonyadi MJ, Asvadi Kermani I, Farassati F, Dastgiri S. Colorectal cancer in iran: molecular epidemiology and screening strategies. J Cancer Epidemiol. 2015;2015:643020. doi: 10.1155/2015/643020. pmid: 25685149.

21. Dolatkhah $R$, Somi $M H$, Kermani IA, Ghojazadeh $M$, Jafarabadi MA, Farassati F, et al. Increased colorectal cancer incidence in Iran: a systematic review and meta-analysis.
BMC Public Health. 2015;15:997. doi: 10.1186/s12889015-2342-9. pmid: 26423906.

22. Winawer S, Fletcher R, Rex D, Bond J, Burt R, Ferrucci J, et al. Colorectal cancer screening and surveillance: clinical guidelines and rationale-Update based on new evidence. Gastroenterology. 2003;124(2):544-60. doi: 10.1053/gast.2003.50044. pmid: 12557158

23. Bray F, Ren JS, Masuyer E, Ferlay J. Global estimates of cancer prevalence for 27 sites in the adult population in 2008. Int J Cancer. 2013;132(5):1133-45. doi: 10.1002/ijc.27711. pmid: 22752881.

24. Bonita R, De Courten M, Dwyer T, Jamrozik K, Winkelmann R. Surveillance of risk factors for noncommunicable diseases: The WHO STEPwise approach: Summary. Noncommunicable Diseases and Mental Health, World Health Organization, 2001.

25. Vineis P, Wild CP. Global cancer patterns: causes and prevention. Lancet. 2014;383(9916):549-57. doi: 10.1016/S0140-6736(13)62224-2. pmid: 24351322.

26. Smith RA, Cokkinides V, von Eschenbach AC, Levin B, Cohen C, Runowicz CD, et al. American Cancer Society guidelines for the early detection of cancer. CA Cancer ] Clin. 2002;52(1):8-22. pmid: 11814067.

27. Greenwald P. A favorable view: progress in cancer prevention and screening. Recent Results Cancer Res. 2007;174:3-17. pmid: 17302181.

28. Kelsey JL, Gammon MD, John EM. Reproductive factors and breast cancer. Epidemiol Rev. 1993;15(1):36-47. pmid: 8405211.

29. Colditz GA, Cannuscio CC, Frazier AL. Physical activity and reduced risk of colon cancer: implications for prevention. Cancer Causes Control. 1997;8(4):649-67. pmid: 9242482.

30. Moyer VA, Force USPST. Screening for prostate cancer: U.S. Preventive Services Task Force recommendation statement. Ann Intern Med. 2012;157(2):120-34. doi: 10.7326/00034819-157-2-201207170-00459. pmid: 22801674.

31. MacDonald N. Palliative care--the fourth phase of cancer prevention. Cancer Detect Prev. 1991;15(3):253-5. pmid: 1711926. 